\title{
Sustainable Agribusiness: Technology Diffusion Barriers to Support Sustainable Agriculture
}

\section{Fera Yunita and Wawan Dhewanto}

School of Business and Management, Institute Teknologi Bandung, Indonesia

Correspondence Author: Fera Yunita School of Business and Management, Institut Teknologi Bandung, Indonesia

Received date: 22 December 2017, Accepted date: 22 January 2018, Online date: 28 February 2018

Copyright: (C) 2018 Fera Yunita. This is an open-access article distributed under the terms of the Creative Commons Attribution License, which permits unrestricted use, distribution, and reproduction in any medium, provided the original author and source are credited.

\begin{abstract}
This study explores barriers of biotechnology adoption among conventional farmers in developing country. Many studies have discussed about the effect of conventional farming activity towards environment. Some of those studies found that conventional farming activity can cause pollution, especially as the effect of chemical pesticides application for pest control. Biopesticide are one of the biotechnology products which environmentally friendly and therefore can be alternative for farmers to reduce the use of chemical pesticide. However, the use of biopesticide still lack especially among conventional farmers in developing country. This study aims to investigate barriers factors affecting the use of biopesticide as the alternative solution for pest control. Qualitative method was used in this research. The samples were four farmers, two government institutions, one educational institutions, and two farming communities. The result showed that there are two group of barriers. First, barriers of adoption which are consist of economic factor, trust factor, social culture factor, and awareness factor. Second, diffusion of barriers factor which are consist of availability factor, development factor, and diffusion of information factor. One factor is considered as challenge for both group, names nature of biopesticide factor.
\end{abstract}

Keywords: Barriers factor, technology diffusion, sustainable agriculture, technology diffusion, agribusiness

\section{INTRODUCTION}

Based on the result evaluation done by Ministry of Agriculture (2015) towards the development of food crops, there are fundamental problems predicted in the future particularly the period 2015-2019. The problems covering aspects such as environmental degradation and climate change; infrastructure; land and water availability; land ownership; national seed systems and breeding; farmers' access to capital; and agricultural labor (1. Indonesia Ministry of Agriculture, 2015). Related to those emerging problems, government takes several anticipations. One of the steps is promoting sustainable agriculture.

FAO (2014) define sustainable agriculture as "Farming activities that are efficient, safe, quality products oriented, protect and improve the natural environment, improve the welfare of farming communities economically and socially, concerned about the welfare of farmer groups and agricultural labor, and give priority to the safety and health ecosystem" (FAO, 2014). The main concept of sustainable in agricultural production is activity which involving social and economic value, also give priority to health and environment (Flora, C.B., 1992). The implementation of the sustainable agriculture concept in agribusiness hopefully can produce high quality products without threatening the sustainability of agricultural ecosystem. The applications of agricultural technologies that are environmentally friendly, efficient, and effective are key implementation of sustainable agriculture (Bettiol, W., 2011).

Concerning the importance of sustainable agriculture for present and future life, many efforts were done including development of supporting technology. Biotechnology is one of developing technologies to support sustainable agriculture (Sanabria, J., 2014). Specifically, the form of biotechnology in this study is biopesticide. Biopesticide use is highly relates to agriculture production process. Biopesticide take an important role as pest control, to reduce the environmental impact caused by the use of chemicals contained in chemical pesticides (Copping, L.G., 2014).

However, applications of biopesticides among conventional farmers are still very limited in number. This issue is closely connected with technology diffusion process of biopesticides to conventional farmers. Uncontrolled use of chemical pesticide among conventional farmers in developing country is a major problem (Duke, et al., 2010). The use of environment friendly material for agriculture production still lack, due to lack of awareness, lack of information and lack of agriculture technology diffusion (Ojiako, U., B. Aleke, 2011). Diffusion of new innovation in agriculture and biotechnology is important as a bridge between research finding and practice. Generally, the main objective of technology diffusion is to increase performance of organization. Performance of organization consists of managing production cost, producing high quality product, maintaining business networking, and increasing production capability (Lechman, E., 2013). In this study, the main objective of biopesticide diffusion focusing in the capability of agribusiness to maintains business from social, economic, and environmental aspect (Marshall, A., 2000)

Therefore, in terms of agribusiness, biopesticide diffusion is very important for longer time period and future value. Despite its importance, research about biopesticide diffusion is lack and need to be encouraged.

This study analyzed the barriers in biopesticide diffusion to conventional farmers, based on two research questions:

1. What are the obstacles that occur in the process of diffusion biopesticides?

2. Who are the key actors or facilitators that can play the role in supporting diffusion of biopesticides technology among conventional farmers?

Diffusion of technology in agricultural sector is not only based on individual decision. There are many stakeholders engaging in this process. To fulfill the needs of suitable analysis, this research used qualitative approach

Literature review:

Sustainable Agriculture: 
Sustainable agriculture term in developing country is starting to be more popular especially among conventional farmers. The collaboration between academician and farmers has increase farmer's interest to know more about sustainable agriculture (Christoffel, d.B., M. Suvedi, 2000). Despite that fact, the implementation of sustainable agriculture still low due to lack of supported infrastructure, and also lack of understanding and trust to bring sustainable agriculture into practice (Carolan, M.S., 2006).

Francis and Youngberg (1990) define sustainable agriculture as "a philosophy based on human goals and on understanding the long-term impact of our activities on the environment and on other species. Use of this philosophy guides our application of prior experience and the latest scientific advances to create integrated, resource- conserving, equitable farming systems. These systems reduce environmental degradation, maintain agricultural productivity, promote economic viability in both the short and long term, and maintain stable communities and quality of life." (Francis, C.A. and Youngberg, 1990). FAO (2014) also define sustainable agriculture as "Farming activities that are efficient, safe, put quality products as priority, protect and improve the natural environment, improve the welfare of farming communities economically and socially, concerned about the welfare of farmer groups and agricultural labor, and give priority to the safety and health ecosystem" (FAO., 2014).

Based on the two definitions to create sustain agriculture, there are at least three principles of developmental process, they are environmental; economic; and social (Füsun, Boz, and Tatlidil, 2009). (Goodland 1995). These three dimensions are integrated and have the same values to create sustainable agriculture (Christoffel and Suvedi, 2000).

The practical objectives of sustainable agriculture, was stated by Benbrook (1991) : “(1) More thorough incorporation of natural processes such as nutrient cycling, nitrogen fixation, and beneficial pest-predator relationships into the agricultural production process; (2) reduction in the use of off-farm inputs with the greatest potential to harm the environment or the health of farmers and consumers; (3) productive use of the biological and genetic potential of plant and animal species; (4) improvement in the match between cropping patterns and the productive potential and physical limitations of agricultural lands; and (5) profitable and efficient production with emphasis on improved farm management, prevention of animal diseases, optimal integration of live stock and cropping enterprises, and conservation of soil, water, energy, and biological resources.'” (Benbrook, C.M., 1991)

\section{Biopesticide Diffusion:}

Technology diffusion concept were stated for the first time by Schumpeter, where specifically he discussed about spreading innovation or diffusion of innovation [18]. Schumpeter build "trilogy in technological change". The trilogy consist of "Invention-innovation-diffusion". The first stage called invention process, where it is basically generating of new idea (Lechman, E., 2013). The next step is creating the idea into new product which have economic value or "marketable product". The last stage is diffusion which consider as spreading product to available potential market (Chung, K., S. Wang, 2014). Schumpeter's idea about diffusion of technology became debatable topic, and many scientists found it "mostly linear" (Chung, K., S. Wang, 2014).

Other than Schumpeter, diffusion theory is also analyzed by Roger. Rogers build conceptual model for diffusion, where he is focusing in "communication channel". Roger addressing communication to "process in which participants create and share information with one another to reach a mutual understanding" (Rogers, E.M., 1995). Trough this concept, Roger translated more dynamic definition for diffusion. More flexible, open, and accommodate multidiscipline approach including agriculture technology diffusion.

The importance of technology diffusion is also applied for biopesticide. The use of biopesticide in developing countries such as Indonesia needs to be improved. Developing countries contribute to increase chemical pesticides use in the world. Recent study has found Brazil's chemical pesticide consumption up to US \$ 7,340 billion in 2010 (Bettiol, 2011). Bettiol (2011) also mentions that total sales of biopesticide products only 1\% compare to total sales of chemical pesticides in 2010 (Bettiol, 2011). Reducing the use of chemical pesticides in developing countries need to be encouraged, especially by promoting and introducing the importance of biopesticides.

Diffusion of biopesticide is not easy, especially in some developing countries which the degree of dependence on chemical pesticides is still very high. One of the most challenging barriers in biopesticide diffusion is user adoption. Even though biotechnology believed as technology which can bring significant advantage for ecosystem and health, many form of biotechnology development often create doubt for targetted consumers (Einsiedel, FF., 1997; Flora, C.B., 1992) (Einsiedel, 1997; Gamble et al., 2000). Some of the factors are; fragile to sudden change, economical factor such as cost for technology transfer, and faith in old perception and experience (RQuaye, Yawson, Yawson, and Williams, 2009).

Methodology:

To untie the barriers and difficulties in biopesticide diffusion and adoption is not a simple thing, considering that this problem related to people perception and behavior. To fulfill all the data needed in-depth interview was conducted. the respondents in this research consist of four farmers, two government institutions, two educational institution, two farming communities, and two biopesticide company. All the samples in this study were chosen purposefully. The four farmers are conventional farmers which use chemical pesticide to help production process. The two government institutions are institutions which responsible to handle agriculture production and national food security, in addition they own field staff to evaluate pest control activity among the farmers.

The educational institutions and farmers communities was chosen based on recommendation from the two government institutions, based on their participation and understanding towards pest control. All the data in this research were transcribed and analyze using open coding.

\section{RESULT AND DISCUSSION}

\section{Barrier Factors:}

Trough the interviews and online observation, several barriers factors were found. Since the perception, position, and task among respondents are different, the adoption barriers will have classified into two groups. They are biopesticide supplier group, and biopesticide users group. Biopesticide supplier group consist of Government Institution (GI 1 and GI 2), Educational Institution (EI), Farming Community (FC 1 and FC 2), and Biopesticide Company (BC). Biopesticide user group consist of Farming Community (FC1 and FC2) and Farmers (F1- F4). FC involve in both group, because community also takes important role in information dissemination either as facilitator or mentor. In the other hand FC also user of the technology itself, since the organizers are also farmers.

\section{Barriers from Biopesticide Users Group:}

Economic Factor:

Economic factor describes respondent's statement which highly related to cost production and their buying power. When they are being asked about making their own biopesticide, one of the expressions commonly said by respondents is "highly cost". Eight out of ten of respondents, expressed this statement. Some of them also stated that "We have enough money to purchase, but it is not worthies". Four of respondents replied, "we have no raw materials (to buy them in large number is not efficient)" and "the raw materials quite expensive". All those expressions also supported by GI1, GI2, and EI which have an experience to give recommendation for farmers to use biopesticide. Based on his experience in biopesticide research, EI stated "some of the materials for biopesticide are expensive and sometimes hard to get". The interviewee also asked F and FC about using commercial pesticide which ready to use. F2 and F3 have no experience in using biopesticide product, while F1 and F4 stated, "it was not effective and the price more expensive than the chemical one" and "the price much more expensive".

\section{Social Culture Factor:}

In this research, social cultural factor involving two main concepts namely cultural and habit. Those are terms that use to describe the usual activity that done by farmers as the solution for pest control. All of the farmers in this research gained information about chemical pesticide by self experience and friend's recommendation. The statements are, "As people here use the brand", "I use this since I begin the business", "Farmers in this area use this" and , "isn't this the common pesticide for rice?". In addition, two of them make it clearer with the statements, "I do not know much, I only know this is (mentioned one chemical pesticide brand) work (for his land)" and "I'm not organic farmer". 
Based on the interview we found that most of the farmers are avoiding risk especially when it comes to new insight or technology, they became very careful. The questions that we asked is what do you think to use biopesticide/natural pesticide? Some of the statements are, "okay, if it is effective" it is mentioned by one farmer, "I'm not sure, the result was not as expected" this statement was mentioned by two farmers. All farmers agreed that biopesticide effect is much slower than chemical pesticide effect, and that time difference is significance for their production. Two of the statements are, "I will face production loss if the larvae keep eating", "Generative phase of plant, is very important for production quality and we need chemical pesticide as well as chemical fertilizer." Trough those statements we can conclude that they will use biopesticide if the effect is the same or more than chemical pesticide they usually use. In other words, their trust towards biopesticide is lies on their satisfaction. Therefore, in this research the next factor that considered as barriers for biopesticide diffusion named as trust.

\section{Awareness Factor:}

Awareness factor is a factor that relate respondent with knowledge that could support their transformation and decision to take the expected action. In this research, respondents expected to transform from chemical pesticide user to biopesticide user. Some of supported statements are, "awareness to transform basically comes from farmer's self decision." This statement stated by GI1. Another supported statement is "Farmer lack of knowledge towards biopesticide existence. Two other respondents also stated almost the same expression.

\section{Barriers from Biopesticide Supplier Group:}

Availability Factor:

Availability factor in this research highly related with concept "easy to get" and "easy to use". In other words, easiness is one of the important things for farmers to use biopesticide. The statements supported this assumption are, "to long to make it by myself", "I have no raw materials here" , "I have experience using biopesticide product once from agriculture exhibition". Beside that statements, two farmers did not recognize any brand of biopesticide that ready to use, this fact recognized trough the statement, "where to get those biopesticide product?" and "what's the name of the product?". When this fact is confirmed to biopesticide company (BC), he also stated that biopesticide company is not yet much especially in Indonesia, due to market limitation. They also stated that their loyal costumer still dominated by organic farmers and home scale farming consumers. He also admitted that those fact were caused by the price of biopesticide, which is almost twice more expensive than chemical pesticide.

Biopesticide Development Factor:

Create their own biopesticide formula is one way to start using natural toxin pest control, but most of the farmers do not interested. This factor has a strong relation with previous factor, that is availability factor. The absence Biopesticide development needs to be increased, but there are many obstacles found during its development. By interviewed with biopesticide company (BC), and educational institution (EI) there were several facts found. First, raw material is very limited. $\mathrm{BC}$ stated that there are some specific materials which number are very limited, this fact recognizes by his statement, "sometimes it is hard for us to get some raw materials". EI also met the same problem and described with the statement, "we need to go far away to get raw materials". Second, to produce biopesticide needs a long research before commercializing. EI statement was, "before we confirm that the result of our research is good we need to test it either in the lab or directly in the field, and the result is often not as expected. Therefore, we need to continue in the next research". BC also stated that research and development department in his company also struggle to find good biopesticide formula. Third, high cost of development. EI stated "to do field test we need amount of raw materials, so it was rather expensive". BC also stated almost the same statement, "in a start phase, need to invest much especially for field test."

\section{Nature of Biopesticide Factor:}

This factor considers as problem that basically comes from the biopesticide itself. The recent condition of biopesticide that makes consumer rejects to adopt, and makes producer face the challenge. Four of respondents which are GI1, GI2, EI1, and EI2, stated almost the same statements that biopesticide is hard to formulate, weak toxication, and need to be applied more often than chemical pesticide".

\section{Diffusion of information factor:}

This factor refers to diffusion of information process by biopesticide supplier. To increase awareness about biopesticide, user should have enough knowledge about biopesticide itself. The supported statements are, "We don't know much about biopesticide." , "I only gain information from peers." , " How to make biopesticide actually?".

All the barriers factors and supported statements were provided in Table 1.

Table 1: Barriers Factors in Biopesticide Diffusion

\begin{tabular}{|c|c|}
\hline Barriers Factors from users & \\
\hline $\begin{array}{l}\text { Ecomomic Factor } \\
\text { - High cost } \\
\text { - Irotefficient } \\
\text { - Affordabie }\end{array}$ & \\
\hline 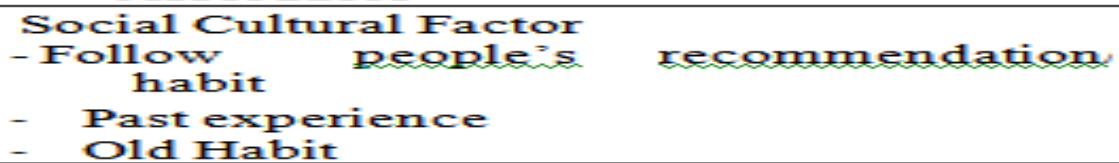 & \\
\hline $\begin{array}{l}\text { Trust Factor } \\
\text { - Sheptic } \\
\text { - Fased on self satisfaction }\end{array}$ & \\
\hline $\begin{array}{l}\text { Awareness Factor } \\
-\quad \text { Igrore } \\
\text { - Careless }\end{array}$ & $\begin{array}{l}\text { Wature of } \\
\text { biopesticide }\end{array}$ \\
\hline $\begin{array}{l}\text { Barriers Factors from UJers } \\
\text { Availability Factor }\end{array}$ & $310 \%$ \\
\hline $\begin{array}{l}\text { - Raw ruaterial awailability } \\
\text { - Ready to use } \\
\text { - Affordable }\end{array}$ & $\begin{array}{l}\text { Wioderate } \\
\text { effect }\end{array}$ \\
\hline 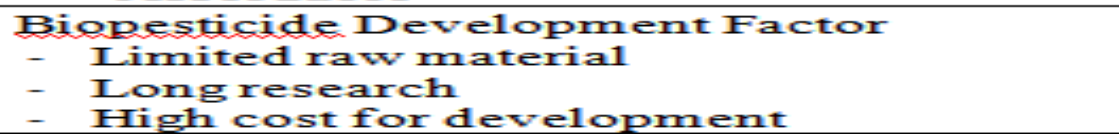 & $\begin{array}{l}\text { FIard to } \\
\text { formutiate }\end{array}$ \\
\hline $\begin{array}{l}\text { Diffusion of information factor } \\
\text { - Unaware } \\
\text { - Iack information } \\
\text { - Iack of adwice }\end{array}$ & \\
\hline
\end{tabular}


For agricultural industry in Indonesia, access to finance and high production cost are the main issues for farmers. They are often struggling to cover cost of pesticide, fertilizer, farming tools, labor incentive, etc. When they market their agriculture product, they also have to compete with import product which sometimes has better quality and lower price. Therefore, purchase new technology which obviously has high uncertainty towards the production result, will cause fragile especially for production loss. Therefore, the economic barriers tend to be the most important for farmers. Previous research about technology acceptance in mechanized cultivation in Iran, also found that economic factor is the most considerable factor for farmers in accepting new technology (Rodriguez, et al., 2009)(Kazemi, Omidi, Hosseini, and Lashgarara, 2015).

For farmer, accept new technology such biopesticide to compete with chemical pesticide which gained market trust for centuries, means taking a high risk. In addition, based on their experience, biopesticide showed slower reaction for pest control. Toxic level of biopesticide also lower than chemical pesticide, and it is easily decomposed by nature, thus farmer needs to rep eat biopesticide application in their farm more often than the chemical one. The fact that biopesticide's price often more expensive than the chemical pesticide also adding farmer's reasons list to not using biopesticide. Therefore psychologically, their trust towards biopesticide is low. One respondent also stated that he is not interested in organic farming because the result of using organic pesticide (biopesticide) is not as good as chemical pesticide. In other words, the farmers have a high expectation towards chemical-based agriculture and set a lower expectation towards non-chemical based agriculture.

Word of mouth information among the farmers also takes an important influence in new technology acceptance. Agricultural industry especially in smallmedium scale usually involves and relies in societies around. They tend to do farming activity collectively and recognize farming process of each farmer in the same area. They also share information and experience about bad or good product for farming. If someone disappointed about one product, the information will be spread to all farmers surrounding and become collective perception. Therefore, social culture needs to be consideration for biotechnological diffusion.

Availability factor and biopesticide development factor are the next problem faced in biopesticide diffusion. Farmers' access to biopesticides is still very limited. Biopesticides are widely used by practitioners of organic farming, but not yet widely diffused in the conventional farmers. In fact, the number of conventional farmers more than the number of organic farmers (Rodriguez, et al., 2009). Conventional farmers need to use biopesticides as a way to maintain the balance and proportion of chemicals pesticide use in agricultural production (Schmidt, et al., 2008). Thus, the diffusion of biopesticides against conventional farmers should be increased.

Compare to previous research, results of this research supporting several previous researches about diffusion of new technology in agriculture sector. In the previous research about constraints in diffusion of new farm technology in dry farming, found that believe in traditional farming, lack of awareness, high cost for technology transfer, and financing problem were the main problems faced in diffusing new technology (Rajesh, R., S. Varadarajan, 2000). Technical problems also become the main concern in diffusion of tractor technology, where development of new technology needs to be evaluated and increase (Martini, D.D.U.F.F.Y., E. Silberberg, 2006). The development of technology very important to answer farmers need and capability, therefore chance of adoption new technology also increase.

Key Actor for Diffusing Biopesticide:

To investigate the key facilitator in biopesticide diffusion, two main questions were asked specifically to four farmers. Those questions are:

1. Where do you get the information about chemical pesticide that you use now?

2. Where do you get the information about biopesticide? Question number one is use to investigate, what/who are the influence of farmer's decision in using certain technology. Question number two is use to investigate the key facilitator which can distribute new technology.

For question number one, all of the answer almost the same, they stated that friend's recommendation was their main consideration. Some of them add that they use one pesticide brand based on his experience. For question number two, three of the farmers agreed farmer community was the first institution which introduced them to biopesticide. Most of the farmers have joined short seminar in farmer community about biopesticide. The source informant in those short seminars mainly government institution trough farming community.

Based on the interview result, common experience is very important to gain trust from farmer. They tend to accept recommendation based on familiarity, social trust, common occupation, and people with the same experience. When GI, BC, and EI want to organize seminars or counseling, they utilize lane farmer groups as a facilitator between them and the farmers. Besides effective in gathering people, farmers' groups also have social and economic closeness with farmers.

\section{Contribution and recommendation:}

This research contributes to provide information of important factors which could be the barriers for biopesticide diffusion to enter international market, and how multiple institution could play important part to encourage adoption of biopesticide. This research also helps to define key actor in diffusing biopesticide.

Conclusion:

Biopesticide existence as the solution for pest control need to be encouraged, to support sustainable agriculture concept which formulated to increase quality of agriculture industry, either economically as well as socially and environmentally. Technology diffusion process plays an important role in efforts to optimize the application of technology. However, developing countries are still experiencing problems in the diffusion of this technology. Some of the problems faced are related to financing, public acceptance, limited facilities and culture. Therefore, barriers factors for biopesticide diffusion cannot be neglected. The role of farmer community as the institution which gain high trust from farmers, and potentially become the key facilitator for biopesticide diffusion should be encourage by all the institution which have concern in biopesticide development.

\section{REFERENCES}

Benbrook, C.M., 1991. Introduction (in Banr's sustainable agriculture research and education in the field: A proceedings) National Academy Press, Washington, D.C.

Bettiol, W., 2011. Biopesticide use and research in brazil. Outlooks on Pest Management, 22(6): 280-283. doi:http://dx.doi.org/10.1564/22dec10.

Bettiol, W., 2011. Biopesticide use and research in brazil. Outlooks on Pest Management, 22(6): 280-283. doi:http://dx.doi.org/10.1564/22dec10.

Carolan, M.S., 2006. Social change and the adoption and adaptation of knowledge claims: Whose truth do you trust in regard to sustainable agriculture? Agriculture and Human Values, 23(3): 325-339.

Christoffel, d.B., M. Suvedi, 2000. Farmers' definitions, goals, and bottlenecks of sustainable agriculture in the north-central region. Agriculture and Human Values, 17(4): 347-358.

Christoffel, d.B., M. Suvedi, 2000. Farmers' definitions, goals, and bottlenecks of sustainable agriculture in the north-central region. Agriculture and Human Values, 17(4): 347-358.

Chung, K., S. Wang, 2014. Technology evolution, diffusion, and regional development : the flat panel display industry in east asia. International Journal of organizational innovation, 6(3): 85-95.

Copping, L.G., 2014. Biopesticides: Making integrated pest management work for farmers and growers. Outlooks on Pest Management, 25(3), 200-204. doi:http://dx.doi.org/10.1564/v25_jun_02

Duke, S.O., C.L. Cantrell, K.M. Meepagala, D.E. Wedge, N. Tabanca, K.K. Schrader, 2010. Natural toxins for use in pest management. Toxins,2(8): $1943-$ 1962. doi:http://dx.doi.org/10.3390/toxins2081943

Einsiedel, FF., 1997. Biotechnology and the Canadian Public. Report on a 1997 National Survey and Some International Comparison. University of Calgary,

Calgary, Canada.

FAO, 2014. Development Agenda and the Millennium Development Goals. http://www.fao.org/post-2015-mdg/14- themes/sustainable-agriculture/en/.

29 September 2015.

FAO., 2014. Development Agenda and the Millennium Development Goals. http://www.fao.org/post-2015-mdg/14- themes/sustainable-agriculture/en/. 29 September 2015. 
Flora, C.B., 1992. Building sustainable agriculture: A new application of farming system research and extension. Journal of Sustainable Agriculture, $\quad 2$ : 37-49. doi:10.1300/J064v02n03_04.

Flora, C.B., 1992. Building sustainable agriculture: A new application of farming system research and extension. Journal of Sustainable Agriculture, 2: $37-$ 49. doi:10.1300/J064v02n03 04.

Francis, C.A. and Youngberg, 1990. "Sustainable agriculture : An overview," pp: 1-23. New Yor : Wiley.

Fusun Tatlidil, F., I. Boz, H. Tatlidil, 2009. Farmers' perception of sstainable asgriculture and its determinants : A case study in Kahramanmaras province of Turkey. Environment, development, and sustainability, 11(16): 1091-1106. Indonesia Ministry of Agriculture, 2015. Agriculture Strategic planning. www.pertanian.go.id. 29 Sepetember 2015 Lechman, E., 2013. New technologies adoption and diffusion patterns in developing countries. An empirical study for the period 2000- 2011.Equlibrium, 8(4): 79-106.

Lechman, E., 2013. New technologies adopyion and diffusion patterns in developing countries. An empirical study for the period 2000- 2011.Equlibrium, 8(4): $79-106$

Marshall, A., 2000. Sustaining sustainable agriculture: The rise and fall of the fund for rural america. Agriculture and Human Values, 17(3): 267-277.

Martini, D.D.U.F.F.Y., E. Silberberg, 2006. The diffusion of tractor technology. The Journal of Economic History, 66(2): 354.

Ojiako, U., B. Aleke, 2011. Symbols as cultural expressions of technology diffusion. Society and Business Review, 6(3): 198-213. doi:http://dx.doi.org/10.1108/17465681111170966

Rajesh, R., S. Varadarajan, 2000Constraints in diffusion of new farm technology in dry farming region: A critical analysis. Indian Journal of Agricultural Economics, 55(3): 563.

Rodriguez, J.M., J.J. Molnar, R.A. Fazio, E. Sydnor, MJ. Lowe, 2009. Barriers to adoption of sustainable agriculture practices: Change agent perspectives.

Renewable Agriculture and Food Systems, 24(1): 60-71. doi:http://dx.doi.org/10.1017/S1742170508002421

Rogers, E.M., 1995. Diffusion of innovations. Collier macmillan publishers: New York

RQuaye, W., I. Yawson, RM. Yawson, I.E. Williams, 2009. Acceptance of biotechnology and social-cultural implications in ghana. African Journal of Biotechnology, 8(9): 1997-2003. doi:http://dx.doi.org/10.5897/AJB09.124

Sanabria, J., 2014. Environmental biotechnology research: Challenges and opportunities in latin america. Journal of Agricultural and Environmental Ethics,27(4): 681-694. doi:http://dx.doi.org/10.1007/s10806-014-9502-2

Schmidt, M., W. Wei, A. Polthanee, N.T. Lam, S. Chuong, L. Qiu, H. Zhou, 2008. 